Article

\title{
Nonlinear Effects of Urbanization and Outward Foreign Direct Investment on Carbon Emissions in China
}

\author{
Ming $\mathrm{Yi}^{1}{ }^{1}$, Mengqi Gong ${ }^{2, *}$, Ting $\mathrm{Wu}^{1}$ and Yue Wang ${ }^{3}$ \\ 1 Research Center of Resource and Environmental Economics, China University of Geosciences, \\ Wuhan 430074, China; yiming@cug.edu.cn (M.Y.); wuting9919@gmail.com (T.W.) \\ 2 School of Economics, Huazhong University of Science \& Technology, Wuhan 430074, China \\ 3 Department of Urban Planning and Design, The University of Hong Kong, Hong Kong SAR 999077, China; \\ ywan86@hku.hk \\ * Correspondence: gongmengqi@hust.edu.cn; Tel.: 0086-027-6788-3201
}

Received: 24 October 2018; Accepted: 21 November 2018; Published: 26 November 2018

\begin{abstract}
It is essential to explore the relationship between China's urbanization, outward foreign direct investment, and carbon emissions, in order to better understand China's carbon emissions reduction target. To this end, the nonlinear Granger causality test and Markov-switching model are applied to analyze the structural effects of urbanization and outward foreign direct investment on domestic emissions, on the basis of time series data from 1984-2016. The results show that the promotion effect of outward foreign direct investment on carbon emissions is increased from low-carbon regime to high-emission regime. Specifically, $1 \%$ increase in OFDI leads to a rise in carbon emissions by $0.064 \%$ and $0.112 \%$ under the former and latter regime respectively. Unlike the effect trend of outward foreign direct investment, the effect of urbanization on carbon emissions is decreased from a high-emission regime $(5.221 \%$ rise in carbon emissions with $1 \%$ increase in the level of urbanization) to a low-carbon regime (3.133\% rise in carbon emissions with $1 \%$ increase in the level of urbanization).
\end{abstract}

Keywords: urbanization; outward foreign direct investment; carbon emissions; nonlinearity

\section{Introduction}

The issue of global warming caused by Greenhouse Gas (GHG) emissions is a global concern. At the Paris Climate Change Conference held in 2015, as the world's largest carbon emission emitter, China made the commitment to reduce its carbon intensity by $60-65 \%$ in 2030 compared with the intensity level in 2005. Some scholars argue that the rapid urbanization accompanied by ever-growing energy consumption is mainly responsible for China's high level of emissions [1,2]. Others believe that the economic development accelerated by urbanization could increase energy efficiency and thus reduces carbon emissions [3-5]. In addition to these two arguments, empirical evidence also shows that the relationship between urbanization and carbon emissions is non-linear [6-9].

Nowadays, the outward foreign direct investment (OFDI) plays an increasingly significant role in China's economic development [10]. However, there is scare research on the investigation of the effect of OFDI on the home country's environment and a unified consensus has not be reached. Some studies have provided evidence that OFDI could lead to an increase in carbon emissions. For instance, Eskeland and Harrison argued that OFDI in developed countries has the characteristic of pollution cost-avoidance [11]. Zhou and Pang found a positive correlation between OFDI and the local environment improvement in developed regions, whereas an opposite situation occurred in less-developed areas [12]. A similar argument was concluded by $\mathrm{Xu}$ and Liu [13,14]. 
To the best of the knowledge of the authors, although there is a large body of research that focuses on the impact of urbanization on carbon emissions, almost no research investigates it within a unique framework of how both urbanization and OFDI affect carbon emissions. Based on China's inter-provincial panel data from 2003 to 2012, the study carried out by Nie and Liu was the only work that developed an integrated OFDI-urbanization-emissions framework to investigate the impacts of the framework on environmental issues [9]. However, this study did not consider the various development stages of urbanization and the heterogeneity of economic growth across regions. To overcome these shortcomings, times series methods $[15,16]$ are useful tools to study the dynamic process between economy and environment when conducting single-country analysis. Considering that linear causality running from output to emissions ignores the interactions between variables, which may produce misleading mistakes [17], the method of nonlinear Granger causality test is applied to examine the interaction between urbanization, OFDI and carbon emissions. Additionally, the Markov-switching model is used to further investigate the interaction, providing theoretic guidance for China's carbon reduction policy.

In summary, this work contributes to the existing research by utilizing the frontier nonlinear time series methods to explore the relationships between urbanization, outward foreign direct investment and carbon emissions in China. In detail, the main objectives of this study are as follows: researching on the relationships between urbanization, OFDI and carbon emissions from time series perspective, analyzing the interaction mechanism between variables by nonlinear Granger causality test, and adopting a Markov-switching model to investigate the non-linear effect of urbanization and OFDI on carbon emissions.

\section{Effects of Urbanization and OFDI on Carbon Emissions}

\subsection{How Urbanization Affects Carbon Emissions}

Urbanization is the process and outcome of the agglomeration of people and resources, characterized by the urban population growth and transformation of employment structure. Energy consumption is the primary source of carbon emissions during this process. A high energy consumption at the beginning of urbanization brings substantial economic benefit, but also results in considerable damage to the environment. This is the so-called economic benefits of carbon emissions under urbanization. However, high emissions in turn restrict further urbanization under the law of diminishing returns to scale. Such a phenomenon shows that there is no simple linear relationship between urbanization and carbon emissions. In order to reduce carbon emissions, it is essential to upgrade the urban production and lifestyle.

Urbanization affects carbon emissions by increasing carbon sources and reducing carbon sinks. The increase of carbon sources is a result of the sharp growth in energy consumption which is due to the transformation of production technology and lifestyle during the urbanization process. Urbanization can be regarded as the transformation from agricultural to non-agricultural communities and it is synchronous with industrialization [18]. Either labor-intensive or resource-intensive industries consume a large amount of energy to produce driving force. As a result, these industries have the characteristics of high-energy consumption and high-emissions. For instance, in the second industrial revolution, electric power replaced the traditional agricultural manual system which greatly improved the efficiency of production and promoted the sharp increase of fossil energy consumption.

Along with industrial development and the large population inflow, the service industries, which aim to facilitate people's production and life, are also developing rapidly. Meanwhile, a large amount of energy is required to improve service quality. Although the proportion of energy consumption in tertiary industries is relatively low compared with the second industries, it is still higher than the agriculture sector. Infrastructure and housing construction also consume a huge amount of materials such as steel and cement, when a growing population moves to urban areas. In addition, transportation 
contributes to a large percentage ( $\geq 20 \%$ ) of energy consumption and carbon emissions (Data source: https:/ /www.iea.org/statistics/). The household demand for energy, such as electricity, also increases.

The reduction of carbon sinks is mainly due to changes in land-use structure and reduced urban metabolic capacity. Natural ecosystems can digest and absorb part of $\mathrm{CO}_{2}$ through forests, grasslands and oceans. However, urbanization needs a lot more space for developing infrastructure and constructions, thus changing natural land to urban use. This weakens carbon sinks and increases carbon sources. Moreover, carbon emissions increase at a rate faster than the metabolic capacity of natural systems.

Figure 1 illustrates the relationship between urbanization and carbon emissions, showing that the impact of urbanization on carbon emissions is not simply a positive feedback process. This impact is not only an expansion effect but also a quality effect. The quality effect is manifested in the following three aspects. Firstly, the rapid flow and agglomeration of resources and elements in the process of urbanization lead to an improvement of production and energy use efficiency. Secondly, the technology spillover effect of agglomeration economy is effective in accelerating the use of clean technology and promoting the quality of low-carbon development in urbanization. Finally, with the diffusion of environmental awareness, the low-carbon target is being achieved through increasing energy use efficiency.

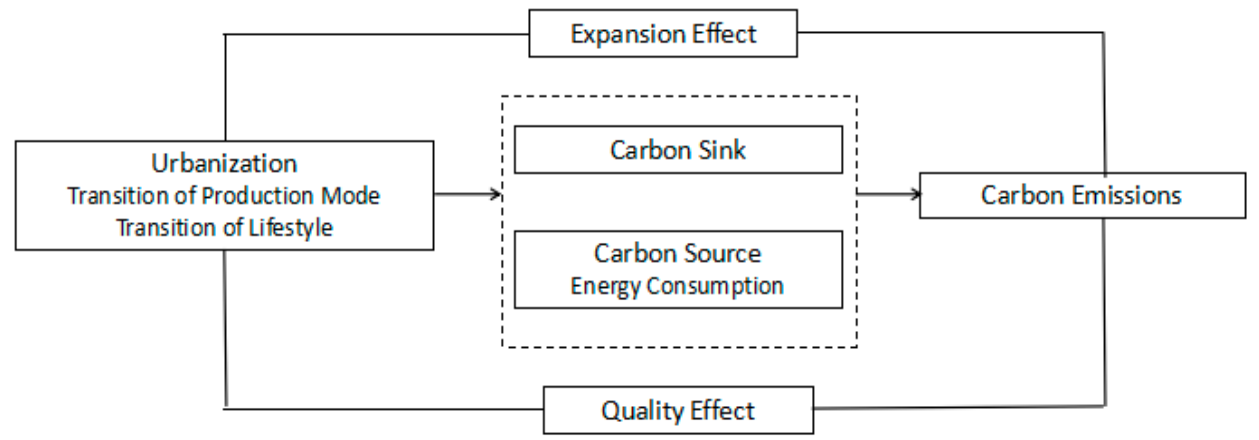

Figure 1. The influence mechanism of urbanization on carbon emissions.

\subsection{Analysis of the Impacts of the OFDI on Carbon Emissions}

There are two controversial theoretical hypotheses for the relationship between OFDI and carbon emissions: Pollution paradise hypothesis and pollution halo hypothesis $[19,20]$. The pollution paradise hypothesis refers to that industries in high emissions-regulated countries transfer their polluting businesses to low-regulated countries based on the principle of firm profit maximization, which deteriorates the environment of the low-regulated countries. On the contrary, the pollution halo hypothesis states that the environment in low-regulated economies could be improved during the transferring of polluting businesses due to the positive technology spillovers from the high-regulated countries. These two effects (polluting businesses transfer effect and reverse technology spillover effect) co-exist with each other and their final results depend on the interaction of the structure of the transfer industry and of its technology.

The relationship between OFDI and carbon emissions depends on the home country's economic development level and its development philosophy. At the first stage, due to the relatively low level of economic development, the home country would often pursue maximum economic benefits while ignoring the environmental benefits. Local resources, such as natural resources and cheap labor, are the main factors that support its economic development. Thus, the OFDI goes to low-level manufacturing sectors with high-energy consumption and high pollution. Due to the lack of environmental protection technology, the manufacturing process will cause serious damage to the home country's environment. The consumption of energy sources, especially coal, increases carbon emissions. China's coal consumption reached $78.4 \%$ of total primary energy in 1995, and currently the proportion still remains quite high [21]. At the second stage, while the development of the OFDI 
and energy-intensive industries boost the economy, deteriorating environmental quality raises a wide concern and becomes a constraint to the economy. To tackle the problem, the polluting country designs policies and re-locates emission-intensive industries to reduce carbon emissions. High emission businesses, which have a high pollution component, are transferred to other countries. For example, China's textile manufacturing is popular in Africa. Concurrently, the polluting country has a channel of reducing emissions through structural optimization and technology upgrading. At the last stage, when the polluting economy is developed and owns advanced technology, the pollution halo hypothesis effect begins to take effect, reducing carbon emissions. This effect works through continuously upgrading technology in high-emission firms and optimizing industrial structure, as well as transferring domestic emission-intensive, energy-intensive industries to other regions through the OFDI from the polluting country.

Above all, the three stages of the OFDI show that carbon emissions follow an inverted U shape in the polluting country. In particular, the OFDI industry's structure and the targeted invested region's technology level are depended on the structural effect and technology effect. When the OFDI focuses on the upgrade of domestic industrial structure and green development, the polluting country would transfer its emission-intensive industries outward and try to obtain technology spillover effect. However, if the polluting country considers its GDP maximization as a main element, it would accept a high amount of emissions in the process of developing the domestic economy. Figure 2 represents how the OFDI affects carbon emissions.
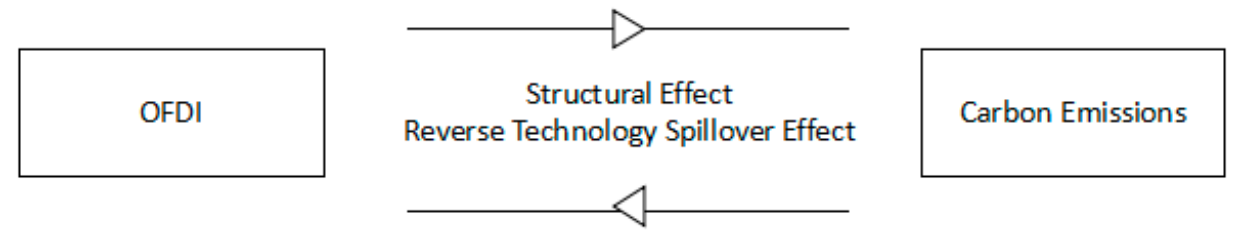

Figure 2. The influence mechanism of OFDI on carbon emission.

\section{Model and Data}

\subsection{Nonlinear Granger Causality Test}

To illustrate the transmission mechanism associated with urbanization, outward foreign direct investment and carbon emissions, the nonlinear Granger causality is applied based on TVAL test [22] method and $T_{n}$ non-parametric test method [23]. Equation (1) holds when time series $Y_{t}$ is not the strict Granger cause of time series $X_{t}$.

$$
\frac{C_{1}\left(m+L_{x}, L_{y}, e\right)}{C_{2}\left(L_{x}, L_{y}, e\right)}=\frac{C_{3}\left(m+L_{x}, e\right)}{C_{4}\left(L_{x}, e\right)}
$$

where $\mathrm{C}_{\mathrm{i}}(\cdot)$ is the joint density correlation integral calculated by Hiemstra and Jones [22]. For the given $X_{t}$ and $Y_{t}, \mathrm{~m}$ represents the leading order of vector matrix $X_{t}$. Parameters $L_{x} \geq 1$ and $L_{y} \geq 1$ represent the corresponding lag order. Under the original hypothesis, for given $m, L_{x} \geq 1, L_{y} \geq 1$ and $e>0$, the statistics of TVAL obey the asymptotic normal distribution as shown in (2).

$$
\sqrt{n}\left(\frac{C_{1}\left(m+L_{x}, L_{y}, e\right)}{C_{2}\left(L_{x}, L_{y}, e\right)}-\frac{C_{3}\left(m+L_{x}, e\right)}{C_{4}\left(L_{x}, e\right)}\right)^{\alpha} \stackrel{d}{\longrightarrow} N\left(0, \sigma^{2}\left(\mathrm{~m}, L_{x}, L_{y}, e\right)\right)
$$

Since the test method of TVAL is prone to cause excessive rejection, Diks and Panchenko [23] further established statistics $T_{n}$ shown in equation (3) to avoid the rejection.

$$
T_{n}\left(e_{n}\right)=\frac{n-1}{n(n-2)} \sum_{i=1}^{n}\left(\hat{f}_{x_{t}, y_{t}, x_{t+1}}\left(x_{i t}, y_{i t}, x_{i t+1}\right) \hat{f_{x_{i}}}\left(x_{i t}\right)-\hat{f}_{x_{i}, y_{i}}\left(x_{i t}, y_{i t}\right) \hat{f}_{x_{i}, x_{t+1}}\left(x_{i t}, x_{i t+1}\right)\right)
$$




$$
\frac{\sqrt{n}\left(T_{n}\left(e_{n}\right)-q\right)}{S_{n}} \stackrel{d}{\longrightarrow} N(0,1)
$$

where $\hat{\mathrm{f}}(\cdot)$ represents the function estimation of local density. Meanwhile, the statistics of $T_{n}$ obey the asymptotic normal distribution shown in (4), where $S_{n}$ represents the asymptotic variance estimation of $T_{n}\left(e_{n}\right)$.

\subsection{Markov-switching Model}

To describe the impact of urbanization and outward foreign direct investment on carbon emissions under different regimes, the Markov-switching model is used based on the nonlinear Granger causality test. Compared with the empirical model based on invariant parameters, the Markov-switching model better reflects the time series structure of China's carbon emissions. The equation (5) shows the model:

$$
\ln C O_{2 t}=\beta_{0}\left(S_{t}\right)+\beta_{1}\left(S_{t}\right) \ln O F D I_{t}+\beta_{2}\left(S_{t}\right) U R_{t}+\varepsilon_{t}
$$

where $\beta_{0}\left(s_{t}\right)$ is the intercept term of the model under different regimes; $\beta_{1}\left(s_{t}\right)$ and $\beta_{2}\left(s_{t}\right)$ are the regression coefficients of each influencing factor under regimes; $\ln \mathrm{CO}_{2}$ represents carbon emissions; $\operatorname{lnOFDI} I_{t}$ represents outward foreign direct investment; $U R_{t}$ represents urbanization rate. $\varepsilon_{t} \mid \Phi_{t-1} \sim N\left(0, \sigma_{s_{t}}^{2}\right)$ is the residual term, where $\sigma_{s_{t}}^{2}$ represents the conditional variance. $\Phi_{t-1}$ represents all the information up to time $\mathrm{t}-1$, and $s_{t} \in\{1,2 \ldots N\}$ shows $\mathrm{N}$ first-order Markov process. The transfer probability satisfies the conditions shown in Equation (6).

$$
\begin{gathered}
P_{\mathrm{ij}}=\operatorname{prob}\left(S_{\mathrm{t}}=j \mid S_{t-1}=i\right) \\
\sum_{\mathrm{j}=1}^{M} P_{i j}=1 ; \forall \mathrm{i}, j \in\{1, \ldots M\} ; P_{\mathrm{ij}} \geq 0
\end{gathered}
$$

\subsection{Data}

The data of China's $\mathrm{CO}_{2}, \mathrm{UR}$ and OFDI flow during the period of 1982 to 2016 are selected to perform analysis. The statistics are shown in Table 1.

Table 1. Descriptive statistics.

\begin{tabular}{llllll}
\hline Variable & Unit & Observation & Average & Maximum & Minimum \\
\hline UR & Urbanization Rate $(\%)$ & 35 & 0.368 & 0.573 & 0.211 \\
$\ln \mathrm{OFDI}$ & OFDI Flows (Thousands of dollars) & 35 & 11.987 & 15.052 & 8.389 \\
$\ln \mathrm{CO} 2$ & $\mathrm{CO}_{2}$ (Ten thousand tons of standard coal) & 35 & 12.743 & 13.640 & 11.782 \\
\hline
\end{tabular}

Note: $\ln \mathrm{CO}_{2}$ represents carbon emissions; lnOFDI represents outward foreign direct investment; UR represents urbanization rate.

According to the formulation provided by the United Nations Intergovernmental Panel on Climate Change (IPCC) formula, the amount of $\mathrm{CO}_{2}$ that are generated from fossil fuels such as coal, oil and gas can be expressed as follows.

$$
\mathrm{CO}_{2}=\sum E_{i} * \theta_{i}
$$

where $E_{i}$ represents the consumption of $i^{\text {th }}$ energy converted into standard coal, and $\theta_{i}$ represents the emission factor of the $i^{\text {th }}$ energy. The data of $\mathrm{CO}_{2}$ amount, which are shown in Table 1, come from the China Energy Statistics Yearbook, with units of 10,000 tons of standard coal. The urbanization rate $(U R)$ is measured by the proportion of urban population in the total population at the end of each year. This data is obtained from the China Statistical Year book (1985-2017) (Data source: National Bureau of Statistics (NBS), 1985-2017). The OFDI data come from the United Nations conference on trade and development (UNCTAD), of which the unit is thousands of dollars. This data is obtained by setting 1982 as the base year and adjusted with the GDP deflator from the World Bank Open Data (https://data.worldbank.org/). 


\section{Results}

\subsection{Nonlinear Test}

To investigate the single integral order of each variable, ADF and PP tests were used to conduct the unit root test. The results are shown in Table 2. It can be found that the data of $\mathrm{CO}_{2}$ and OFDI are the I (1) process, while UR is the I (2) process. This means that carbon emissions, outward foreign direct investment and urbanization do not have the same order sequence. Therefore, the trail test and E-G two-step method are further applied to examine co-integration between non-stationary sequences based on the unit root test. The results show that there exists a long-term co-integration relationship among $U R$, OFDI and $\mathrm{CO}_{2}$, as shown in Table 3.

Table 2. Unit root test.

\begin{tabular}{lllllll}
\hline \multicolumn{3}{l}{ ADF Test } & \multicolumn{5}{c}{ PP Test } \\
\hline & Level & 1st Difference & 2nd Difference & Level & 1st Difference & 2nd Difference \\
\hline $\ln \mathrm{CO}_{2}$ & -0.758 & $-3.768^{* * *}$ & $-8.130^{* * *}$ & -0.589 & $-3.751^{* * *}$ & $-10.737^{* * *}$ \\
$\ln \mathrm{OFDI}$ & -1.370 & $-7.245^{* * *}$ & $-6.406^{* * *}$ & -1.370 & $-7.556^{* * *}$ & $-31.647^{* * *}$ \\
$\mathrm{UR}$ & 1.105 & $-2.417^{* * *}$ & $-9.008^{* *}$ & 2.312 & $-2.411^{* * *}$ & $-8.745^{*}$ \\
\hline
\end{tabular}

Note: ${ }^{* * *}$ respectively means the significant at $1 \%$ significance level; $\ln \mathrm{CO}_{2}$ represents carbon emissions; InOFDI represents outward foreign direct investment; UR represents urbanization rate.

Table 3. Co-integration test.

\begin{tabular}{|c|c|c|c|c|}
\hline \multicolumn{5}{|l|}{ Trace Test } \\
\hline $\begin{array}{l}\text { Hypothesized } \\
\text { No. of CE(s) }\end{array}$ & Eigenvalue & $\begin{array}{l}\text { Trace } \\
\text { Statistic }\end{array}$ & $\begin{array}{l}0.05 \\
\text { Critical value }\end{array}$ & Prob. ** \\
\hline None & 0.485 & 30.503 & 29.797 & 0.041 \\
\hline At most 1 & 0.227 & 8.590 & 15.495 & 0.405 \\
\hline At most 2 & 0.003 & 0.102 & 3.841 & 0.750 \\
\hline \multicolumn{5}{|c|}{ Maximum Eigenvalue Test } \\
\hline $\begin{array}{l}\text { Hypothesized } \\
\text { No. of CE(s) }\end{array}$ & Eigenvalue & $\begin{array}{l}\text { Max-Eigen } \\
\text { Statistic }\end{array}$ & $\begin{array}{l}0.05 \\
\text { Critical value }\end{array}$ & Prob. ** \\
\hline None & 0.485 & 21.913 & 21.132 & 0.039 \\
\hline At most 1 & 0.227 & 8.488 & 14.265 & 0.331 \\
\hline At most 2 & 0.003 & 0.102 & 3.841 & 0.750 \\
\hline
\end{tabular}

Note: ${ }^{* *}$ denotes the significant at $5 \%$ significance level.

Based on the cointegration test result, the VEC model is adopted to test the interaction relationship among $U R, O F D I$ and $\mathrm{CO}_{2}$. This method can filter out linearly dependent data so that the BDS nonlinearity test can be applied to analyze the residuals after the filtering. If the residuals are independent and identically distributed, then the residuals of the sequence have nonlinear characteristics. That is, the nonlinear information in the sequence cannot be fully interpreted. To make the results robust, Table 4 shows the results when dimensioning $\mathrm{m}$ is set to $2,3,4,5,6$, respectively. Clearly, a nonlinear dynamic impact of carbon emissions on OFDI and urbanization can be observed after the filtering of the VEC model. In other words, nonlinear characteristics do exist in the model. Then, the question whether there are nonlinear regimes between variables is explored. Both the TVAL test method proposed by Hiemstra and Jones [22] and $\mathrm{T}_{\mathrm{n}}$ non-parametric test method proposed by Diks and Panchenko [23] are used to reveal the non-linear mechanism among UR, OFDI and $\mathrm{CO}_{2}$. In addition, the VEC model is used to test the residuals after filtering to ensure that the strict nonlinear Granger causality between variables could be accurately verified. The results are shown in Table 5 . 
Table 4. BDS test results based on the residuals filtered by the VEC model.

\begin{tabular}{llllll}
\hline $\mathbf{m}$ & $\mathbf{m}=\mathbf{2}$ & $\mathbf{m}=\mathbf{3}$ & $\mathbf{m}=\mathbf{4}$ & $\mathbf{m}=\mathbf{5}$ & $\mathbf{m}=\mathbf{6}$ \\
\hline $\ln \mathrm{CO}_{2}$ & -0.001 & -0.004 & $-0.011^{*}$ & $-0.021^{* *}$ & $-0.033^{* * *}$ \\
$\ln \mathrm{OFDI}$ & $0.005^{* * *}$ & $0.015^{* * *}$ & $0.029^{* * *}$ & $0.037^{* * *}$ & $0.043^{* * *}$ \\
UR & $0.004^{* * *}$ & $0.007^{* *}$ & 0.002 & -0.003 & 0.003 \\
\hline
\end{tabular}

Note: The optimal lag order of the VEC model is determined according to the information criterion of AIC and SIC; $*, * *, * * *$ denote the results at $10 \%, 5 \%$ and $1 \%$ significance level, respectively; $\ln \mathrm{CO}_{2}$ represents carbon emissions; InOFDI represents outward foreign direct investment; $U R$ represents urbanization rate.

Table 5. Bilinear filtering nonlinear Granger causality test based on the VEC model.

\begin{tabular}{|c|c|c|c|c|c|c|c|c|}
\hline \multirow[b]{2}{*}{$L_{x}=L_{y}$} & \multicolumn{2}{|c|}{$\operatorname{lnCO} \mathrm{O}_{2} \neq \rightarrow U R$} & \multicolumn{2}{|c|}{$U R \neq \rightarrow \ln \mathrm{CO}_{2}$} & \multicolumn{2}{|c|}{$\ln \mathrm{CO}_{2} \neq \rightarrow \ln \mathrm{OFDI}$} & \multicolumn{2}{|c|}{$\ln \mathrm{OFDI} \neq \rightarrow \ln \mathrm{CO}_{2}$} \\
\hline & TVAL & $T_{n}$ & TVAL & $\mathbf{T}_{\mathbf{n}}$ & TVAL & $T_{n}$ & TVAL & $T_{n}$ \\
\hline 1 & -2.401 & 2.459 & 0.574 & 0.452 & -1.182 & -1.473 & 0.897 & 1.126 \\
\hline 2 & -1.641 & -1.280 & 1.051 & 1.048 & -0.454 & -0.227 & 0.097 & 0.023 \\
\hline 3 & -1.014 & -1.106 & 0.793 & 0.449 & -0.149 & 0.029 & 0.764 & 0.411 \\
\hline 4 & -0.824 & -0.826 & $1.313^{*}$ & 0.763 & -0.554 & -0.482 & 1.056 & 0.566 \\
\hline 5 & -0.997 & -0.890 & $1.560 *$ & $1.376^{*}$ & -0.032 & -0.227 & $1.560 *$ & 1.408 * \\
\hline 6 & -0.134 & 0.866 & $1.561 *$ & 1.049 & -0.431 & -0.159 & $1.561 *$ & 1.297 * \\
\hline 7 & -0.289 & 0.649 & 1.424 * & 0.921 & -0.860 & -0.727 & $1.424 *$ & 1.173 \\
\hline
\end{tabular}

Note: ${ }^{*}$ denotes the significant at $10 \%$ significance level; $\ln \mathrm{CO}_{2}$ represents carbon emissions; $\ln \mathrm{OFDI}$ represents outward foreign direct investment; $U R$ represents urbanization rate.

According to the results shown in Table 5, it can be found that there is a one-way nonlinear Granger relationship between urbanization and carbon emissions. In other words, urbanization is a nonlinear Granger cause of carbon emissions, but carbon emissions are not a nonlinear Granger cause of urbanization. Thus, as for China, the increase of carbon emissions is inevitable in the process of accelerating urbanization. As there is no nonlinear Granger causality from carbon emissions to urbanization, reducing carbon emissions will not significantly impact the urbanization. Like the relationship between urbanization rate and carbon emissions, OFDI is the nonlinear Granger cause of carbon emissions, but carbon emissions are not the nonlinear Granger cause of OFDI. Therefore, China's Going Global strategy, the main body of which is OFDI, will have a great impact on carbon emissions. However, the reduction of carbon emissions will not affect China's OFDI. In view of this, China should strengthen carbon emissions reduction and pay attention to environmental pollution in the process of accelerating urbanization and the development of Going Global strategy.

\subsection{Markov-switching Model Estimation}

According to the results of the nonlinearity test and nonlinear Granger causality test, the residuals of either a single variable or between variables have a significant nonlinear relationship. Both the urbanization rate and OFDI are the nonlinear Granger causes of carbon emissions. Based on this, a Markov-switching model is used to further test the difference of the structural impact of urbanization rate and OFDI on carbon emissions under different regimes. It also explored the probability of China maintaining the current high carbon regime and how to reduce the carbon emissions in China. Regression results are shown in Table 6. 
Table 6. Results of the Markov-switching model.

\begin{tabular}{lll}
\hline & Regime 1 & Regime 2 \\
\hline Intercept & $10.116^{* * *}$ & $10.278^{* * *}$ \\
& $(0.092)$ & $(0.261)$ \\
InOFDI & $0.064^{* * *}$ & $0.112^{* * *}$ \\
& $(0.012)$ & $(0.043)$ \\
UR & $5.221^{* * *}$ & $3.133^{* * *}$ \\
& $(0.189)$ & $(0.727)$ \\
\hline Transition probabilities: & & \\
\hline & Regime 1 & Regime 2 \\
\hline Regime 1 & 0.935 & 0.111 \\
Regime 2 & 0.065 & 0.889 \\
AIC -77.085 & BIC -46.421 & logLike 44.543 \\
\hline
\end{tabular}

Note: *** respectively means the significant at $1 \%$ significance level; The brackets of the regression coefficients correspond to the standard error; $\ln \mathrm{CO}_{2}$ represents carbon emissions; $\ln \mathrm{OFDI}$ represents outward foreign direct investment; $U R$ represents urbanization rate.

In the first regime, $1 \%$ increase in OFDI leads to a rise in carbon emissions by $0.064 \%$. The increase of OFDI plays a driving role in carbon emissions, which is significant at $1 \%$ level. Under the second regime, $1 \%$ increase in OFDI promotes the increase of carbon emissions by $0.112 \%$. This conclusion is consistent with the findings obtained by $\mathrm{Xu}$ and Liu $[13,14]$. It seems that China has not transferred from energy-intensive industries through OFDI during the study period. There are two possible reasons to explain this statement: First, the targeted investee countries are mainly developing economies. China's OFDI has the feature of resource-seeking, which is lack of advanced technology, making it difficult to form positive environment-technology feedback so that carbon emissions rise [24-26]. In addition, the increase in OFDI would promote a rise in the second industry with high-emissions and high-energy consumption features, causing more carbon emissions.

The effect of urbanization on carbon emission declines from regime 1 to regime 2. Under regime 1 (i.e., low-emission regime), $1 \%$ increase in the level of urbanization leads to a $5.221 \%$ rise in carbon emissions, while the level of emission rise becomes 3.133\% under regime 2 (i.e., high-emission regime). It shows that urbanization has positive effects on carbon emissions. This conclusion is consistent with Bai Yuping et al. [27]. They argued that the share of urban population can increase residential carbon emissions even pasting the demarcation point (75\%) in China's urban agglomerations. However, along with the rising level of urbanization in China, the social infrastructure and technological level will be improved. At the same time, the urban population requires better energy quality, for example, clean energy such as natural gas, which will reduce carbon emissions.

Lastly, according to the transition probability matrix of carbon emissions, the status of carbon emissions has very strong sustainability in both regime 1 and regime 2 . If carbon emissions in period $t$ are under regime 2 (i.e., a high-emissions mechanism), the probability of keeping the high emission status in period $t+1$ is estimated to be 0.889 , which implies only a probability of 0.111 for high-emissions status moving to low-emissions status. Similarly, if carbon emissions are under the regime 1 (i.e., low-emission regime) in period $t$, the probability of staying at the same regime in next period is estimated to be 0.935 , implying only a probability of 0.065 of transiting to regime 2 . To a certain extent, this shows that it is difficult to reduce China's carbon emissions at this stage. Therefore, it is necessary to pay attention to the phased characteristics of urbanization and OFDI.

Figure 3a shows the transition probability of a low carbon emissions regime to a high carbon emissions regime. Figure $3 \mathrm{~b}$ shows the transition probability of a high carbon emissions regime to a low carbon emissions regime. In this figure, horizontal axis represents time, with values ranging from 0 to 35, which correspond to the years from 1982 to 2016. The vertical axis indicates the transition probability between a high carbon emissions regime and a low carbon emissions regime. The sum of the transition probability of carbon emissions in different regimes is one in the same period. For 
example, the results of Markov-switching in Figure 3 demonstrate that from 2009 to 2016 (i.e., 28-35 of the horizontal axis), the probabilities of China locates in a high carbon emissions regime and a low carbon emissions regime are 0.889 and 0.111 , respectively. The sum of these two probabilities is 1 . From 1982 to 1992 (0-11 on the horizontal axis), the probabilities that China locates in a low carbon emissions regime and a high carbon emissions regime are 0.935 and 0.065 , respectively, the sum of which is 1 . It can be found that a significant nonlinearity in China's carbon emissions from Figure 3, where either a high emissions level or a low emissions level lasts for a long time during the studied period. This is consistent with the analysis of Markov-switching. Considering that China now is a high carbon economy, it is thus essential to understand the interaction among urbanization, OFDI and carbon emissions so that reasonable carbon reduction policies can be made.

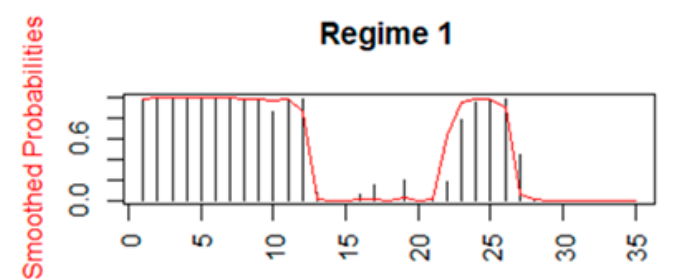

(a) Transition probability of regime 1 to regime 2
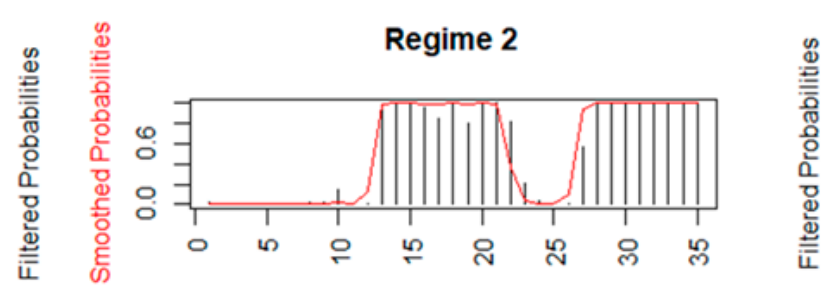

(b) Transition probability of regime 2 to regime 1

Figure 3. The smooth probability distribution.

\section{Conclusions}

By using the data of urbanization rate, OFDI and carbon emissions in China from 1982 to 2016, the method of nonlinear analysis is used to investigate the effect of urbanization and OFDI on carbon emissions, which shows that there exists a co-integration relationship among the three variables. The BDS results show that the residues of the rate of urbanization, OFDI and carbon emissions are significant non-linear based on the VEC model. Non-linear Granger causality reflects that the rate of urbanization and OFDI are sources of the increase in carbon emissions. However, the relationship does not hold in turn. Also, the Markov-switching model shows the effect of urbanization and OFDI on emissions under different scenarios. Each $1 \%$ increase in OFDI promotes a $0.064 \%$ rise in emissions in regime 1 whereas a $0.112 \%$ rise in emissions is found in regime 2 . The effect of urbanization on carbon emissions declines from regime 1 to regime 2. That is, each $1 \%$ increase in urbanization leads to a $5.221 \%$ rise in emissions under regime 1, whereas a $3.133 \%$ growth is found in regime 2. Finally, the transfer probability matrix shows that if China's carbon emissions are in the first mechanism in the $t$ phase, then the probability of maintaining the first mechanism in the $t+1$ phase is 0.935 , and the probability of transferring to the second mechanism is only 0.065 . If carbon emissions are in the second mechanism in the $t$ phase, the probability of maintaining the second mechanism in the $t+1$ phase is 0.889 , and the probability of transferring to the second mechanism is only 0.065 . Therefore, it is considered to be very difficult for China to transfer from a high-carbon emission mechanism to a low-carbon emission mechanism at this stage.

In order to alleviate China's carbon emissions, it is important to know how to grasp the carbon emission effect of outward direct investment and urbanization rate. First of all, the OFDI needs to be developed according to the following ways. The scale of technology-oriented OFDI requires further expansion so that domestic industries can access advanced green technologies from overseas. In addition, high-emission and high-energy consumption industries need to be transferred outward. Industry transfer would benefit China's industrial structure upgrade. Second, carbon emissions have to be consistent with the path of economic development. Since China' urbanization is experiencing a fast-growing period, it is vital to stabilize its rate of urbanization as well as to control carbon emissions. Moreover, increasing the proportion of clean energy such as natural gas to total energy consumption could also help improve environmental technology to reduce China's carbon emissions. 
Author Contributions: Data curation, Ting Wu; Methodology, Yue Wang; Writing—original draft, Mengqi Gong; Writing-review \& editing, Ming Yi.

Acknowledgments: This research was jointly supported by the State Scholarship Fund of the China Scholarship Council, the Fundamental Research Funds for Central Universities of China University of Geosciences (Wuhan) and the Open Funds (Grant No. HBQY2018z12) of Regional Innovation Capabilities Monitoring and Analysis Soft Science Research Base of Hubei Province.

Conflicts of Interest: The authors declare no conflict of interests.

\section{References}

1. Zhang, Y.J.; Liu, Z.; Zhang, H.; Tan, T.D. The impact of economic growth, industrial structure and urbanization on carbon emission intensity in China. Nat. Hazards 2014, 73, 579-595. [CrossRef]

2. Liddle, B. Impact of population, age structure, and urbanization on carbon emissions/energy consumption: Evidence from macro-level, cross-country analyses. Popul. Environ. 2014, 35, 286-304. [CrossRef]

3. Liddle, B. Demographic dynamics and per capita environmental impact: Using panel regressions and household decompositions to examine population and transport. Popul. Environ. 2004, 26, 23-39. [CrossRef]

4. Fan, Y.; Liu, L.C.; Wu, G.; Wei, Y.M. Analyzing impact factors of $\mathrm{CO}_{2}$ emissions using the STIRPAT model. Environ. Impact Assess. Rev. 2006, 26, 377-395. [CrossRef]

5. Sharma, S.S. Determinants of carbon dioxide emissions: Empirical evidence from 69 countries. Appl. Energy 2011, 88, 376-382. [CrossRef]

6. Dong, X.; Yuan, G. China's greenhouse gas emissions' dynamic effects in the process of its urbanization: A perspective from shocks decomposition under long-term constraints. Energy Procedia 2011, 5, 1660-1665. [CrossRef]

7. Maruotti, A. The impact of urbanization on $\mathrm{CO}_{2}$ emissions: Evidence from developing countries. Ecol. Econ. 2011, 70, 1344-1353. [CrossRef]

8. Shahbaz, M.; Sbia, R.; Hamdi, H.; Ozturk, I. Economic growth, electricity consumption, urbanization and environmental degradation relationship in United Arab Emirates. Ecol. Indic. 2014, 45, 622-631. [CrossRef]

9. Yao, X.1.; Kou, D.; Shao, S.; Li, X.Y.; Wang, W.X.; Zhang, C.T. Can urbanization process and carbon emission abatement be harmonious? New evidence from China. Environ. Impact Assess. Rev. 2018, 71, 70-83. [CrossRef]

10. Nie, F.; Liu, H.Y. Carbon emissions effect of China's OFDI evidence from urbanization threshold model. China Popul. Resour. Environ. 2016, 9, 123-131. [CrossRef]

11. Eskeland, G.S.; Harrison, A.E. Moving to greener pastures? Multinationals and the pollution haven hypothesis. J. Dev. Econ. 2003, 70, 1-23. [CrossRef]

12. Zhou, L.; Pang, C.C. Home country environmental effects of China's foreign direct investment-Based on the perspective of regional differences. China Popul. Resour. Environ. 2013, 8, 131-139. [CrossRef]

13. $\mathrm{Xu}, \mathrm{K}$.; Wang, Y. The Influence of China's OFDI on its domestic $\mathrm{CO}_{2}$ emissions: An empirical analysis based on China's provincial panel Data. Int. Bus. Res. 2015, 1, 76-86.

14. Liu, H.Y.; Li, M. The home country effect research of China's OFDI on carbon emissions. J. Ind. Technol. Econ. 2016, 8, 12-18. [CrossRef]

15. De Bruyn, S.M.; van den Bergh, J.C.J.M.; Opschoor, J.B. Economic growth and emissions: reconsidering the empirical basis of environmental Kuznets curves. Ecol. Econ. 1998, 25, 161-175. [CrossRef]

16. Lindmark, M. An EKC-pattern in historical perspective: Carbon dioxide emissions, Technology, Fuel prices and growth in Sweden 1870-1997. Ecol. Econ. 2002, 42, 333-347. [CrossRef]

17. Yang, Z.H. Nonlinear study of the relationship between "economic growth" and "carbon dioxide emissions": A nonlinear Granger causality test based on developing countries. J. World Econ. 2010, 10, 139-160.

18. Lin, B.Q.; Liu, X.Y. China's carbon dioxide emissions under the urbanization process: Influence factors and abatement policies. Econ. Res. J. 2010, 45, 66-78.

19. Walter, I.; Ugelow, J.L. Environmental policies in developing countries. Ambio 1979, 8, 102-109.

20. Letchumanan, R.; Kodama, F. Reconciling the conflict between the 'pollution-haven' hypothesis and an emerging trajectory of international technology transfer. Res. Policy 2000, 29, 59-79. [CrossRef]

21. Chen, S. The Abatement of Carbon Dioxide Intensity in China: Factors Decomposition and Policy Implications. World Econ. 2011, 34, 1148-1167. [CrossRef] 
22. Hiemstra, C.; Jones, J.D. Testing for Linear and Nonlinear Granger Causality in the Stock Price-Volume Relation. J. Financ. 1994, 49, 1639-1664. [CrossRef]

23. Diks, C.; Panchenko, V. A new statistic and practical guidelines for nonparametric Granger causality testing. J. Econ. Dyn. Control 2006, 30, 1647-1669. [CrossRef]

24. Li, L.; Zhang, Z.Y. Is China's Outward FDI Seeking Resources? J. Int. Trade 2012, 2, 146-157. [CrossRef]

25. Jiang, G.H.; Jiang, D.C. Location selection of China's outward investment: Based on investment gravity model of panel data. J. World Econ. 2012, 9, 21-40.

26. Chen, Y.; Ma, L.L.; Zhong, C.B. China's investment determinants for Africa: An empirical analysis from the perspective of resources integrating and institutions. J. World Econ. 2012, 10, 91-112.

27. Bai, Y.P.; Deng, X.Z.; Gibson, J.; Zhao, Z.; Xu, H. How does urbanization affect residential $\mathrm{CO}_{2}$ emissions? An analysis on urban agglomerations of China. J. Clean Prod. 2018, 209, 876-885. [CrossRef]

(C) 2018 by the authors. Licensee MDPI, Basel, Switzerland. This article is an open access article distributed under the terms and conditions of the Creative Commons Attribution (CC BY) license (http://creativecommons.org/licenses/by/4.0/). 